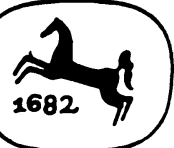

Sammlung Metzler Band 246 
Terry Eagleton

\title{
Einführung in die Literaturtheorie
}

\author{
Aus dem Englischen \\ von
}

Elfi Bettinger und

Elke Hentschel

J. B. Metzlersche Verlagsbuchhandlung

Stuttgart 
Die Orginalausgabe erschien bei Basil Blackwell Publisher Limited, Oxford unter dem Titel »Literary Theory. An Introduction«

(C) Terry Eagleton 1983

\author{
Für \\ Charles Swann \\ und \\ Raymond Williams
}

CIP-Titelaufnahme der Deutschen Bibliothek

\author{
Eagleton, Terry: \\ Einführung in die Literaturtheorie / Terry Eagleton. - Stuttgart \\ : Metzler, 1988 \\ (Sammlung Metzler ; Bd. 246) \\ Einheitssacht.: Literary theory $<\mathrm{dt}$. $>$ \\ ISBN 978-3-476-10246-1 \\ ISBN 978-3-476-03948-4 (eBook) \\ DOI 10.1007/978-3-476-03948-4 \\ ISSN 05583667 \\ NE: GT
}

\title{
SM 246
}

Dieses Werk einschließlich aller seiner Teile ist urheberrechtlich geschützt. Jede Verwertung außerhalb der engen Grenzen des Urheberrechtsgesetzes ist ohne Zustimmung des Verlages unzulässig und strafbar. Das gilt insbesondere für Vervielfältigungen, Übersetzungen, Mikroverfilmungen und die Einspeicherung und Verarbeitung in elektronischen Systemen.

(C) 1988 Springer-Verlag GmbH Deutschland

Ursprünglich erschienen bei J. B. Metzlersche Verlagsbuchhandlung und Carl Ernst Poeschel GmbH in Stuttgart 1988 


\section{Vorwort}

Wenn man den Ausgangspunkt der Veränderung, die die Literaturtheorie in diesem Jahrhundert erfahren hat, auf einen bestimmten Zeitpunkt festlegen wollte, so wäre das Jahr 1917, in dem der junge russische Formalist Viktor Šklovškij seinen bahnbrechenden Essay "Iskusstvo, kak priëm « (Die Kunst als Verfahren) veröffentlichte, keineswegs der schlechteste Vorschlag. Seitdem, und insbesondere in den beiden letzten Jahrzehnten, hat eine auffallende Bereicherung der Literaturtheorie stattgefunden: Die eigentliche Bedeutung von $>$ Literatur<, >Lesen< und >Literaturkritik erfuhr einen tiefgreifenden Wandel. Aber bis auf einen kleinen Kreis von Spezialisten und Enthusiasten hat sich diese theoretische Revolution bisher noch nicht besonders weit verbreitet: ihre volle Auswirkung auf die Literaturstudenten/inn/en und die Leser/innen im allgemeinen steht noch aus.

Das vorliegende Buch soll eine einigermaßen verständliche Darstellung der modernen Literaturtheorie für diejenigen geben, die wenig oder gar keine Vorkenntnisse auf diesem Gebiet haben. Obgleich ein solches Vorhaben naturgemäß Auslassungen und unzulässige Simplifizierungen mit sich bringt, habe ich versucht, den Gegenstand eher 'populär und wissenschaftlich allgemeinverständlich als im negativen Sinne spopulärwissenschaftlich darzustellen. Da es eine >neutrale<, >wertfreie Darstellungsweise meiner Meinung nach nicht gibt, gebe ich meinen Standpunkt durchweg deutlich zu erkennen und hoffe, damit zusätzliches Interesse an dem Buch zu wecken.

Der Ökonom J. M. Keynes hat einmal bemerkt, daß diejenigen Wirtschaftswissenschaftler, die der Theorie ablehnend gegenüberstehen oder ohne sie besser zurechtzukommen behaupten, einfach noch einer älteren Theorie verhaftet sind. Das trifft auch für Literaturstudenten, -kritiker und -wissenschaftler zu. Manche beklagen sich, daß die Literaturtheorie unglaublich esoterisch sei - vermuten darin eine geheimbündlerische, elitäre Enklave, die der Nuklearphysik ziemlich ähnlich ist. Zwar ermutigt literarische Bildung nicht gerade zum analytischen 
Denken; aber Literaturtheorie ist in Wirklichkeit nicht schwieriger als viele andere theoretische Untersuchungen, und sogar um einiges einfacher als manche von ihnen. Ich hoffe, daß das vorliegende Buch einen Beitrag dazu leistet, denen die Angst zu nehmen, die befürchten, daß der Gegenstand ihre Verständnisfähigkeit überschreitet. Einige Student/inn/en und Kritiker/innen verwahren sich auch dagegen, daß die Literaturtheorie 'zwischen den Leser und das Werk< trete. Die einfache Antwort darauf ist, daß wir ohne irgendeine Art von Theorie, wie unreflektiert und unbewußt sie auch immer sein mag, gar nicht erst wüßten, was überhaupt ein >literarisches Werk < ist oder wie wir es lesen sollen. Eine feindselige Einstellung der Theorie gegenüber bedeutet normalerweise eine Ablehnung der Theorien anderer und ein Übersehen der eigenen. Ein Anliegen dieses $\mathrm{Bu}-$ ches besteht darin, diese Verdrängung aufzuheben und uns ein Wiedererkennen zu ermöglichen.

T.E.

Im Einverständnis mit dem Autor und dem englischen Verlag ist die vorliegende deutsche Ausgabe um das Kapitel »The Rise of English" gekürzt, das den Aufstieg und die Entwicklung der Literaturwissenschaft in Großbritannien und in den USA behandelt. Die dort enthaltene grundsätzliche Auseinandersetzung mit dem New Criticism wurde jedoch beibehalten und an den Beginn des Kapitels über "Strukturalismus und Semiotik « gestellt. Die Anmerkungen der englischen Ausgabe wurden prinzipiell in den Text eingearbeitet. Das Literaturverzeichnis enthält alle vom Autor benutzten Titel (mit den entsprechenden deutschen Ausgaben) sowie weiterführende Literatur für die deutschen Leser und Leserinnen. 


\section{Inhalt}

1. Einleitung: Was ist Literatur? . . . . . . . 1

2. Phänomenologie, Hermeneutik, Rezeptionstheorie .............. 19

3. New Criticism, Strukturalismus und Semiotik . . . . . . . . . . . . . 59

4. Der Poststrukturalismus . . . . . . . . . . 110

5. Die Psychoanalyse . . . . . . . . . . . 138

Schluß: Politische Kritik . . . . . . . . . . . 187

Bibliographie ................ 214

Register . . . . . . . . . . . . . . . . 224 